\title{
Riscos Ocupacionais Evidenciados em uma Unidade de Terapia intensiva Neonatal: Um Estudo de Caso
}

\section{Occupational Risks Evidenced in a Neonatal Intensive Terapy Unity: A Case Study}

\author{
${ }^{1}$ Luciane Cleonice Durante \\ ${ }^{2}$ Natália Alencastro de Albuquerque Lins Turi Marques \\ ${ }^{3}$ Raquel Naves Blumenschein \\ ${ }^{4}$ Joceli Fernandes Alencastro Bettini de Albuquerque Lins \\ ${ }^{1}$ Doutora - Universidade Federal de Mato Grosso (luciane.durante@ hotmail.com) \\ ${ }^{2}$ Arquiteta e Urbanista, Universidade Federal de Mato Grosso (natalialins@yahoo.com.br) \\ ${ }^{3}$ Doutora- Universidade de Brasília (raquelblum@terra.com.br) \\ ${ }^{4}$ Doutora - Universidade Federal de Mato Grosso (joceli.lins@ gmail.com)
}

\begin{abstract}
RESUMO: Este estudo teve por objetivo caracterizar os riscos ocupacionais a que estão expostos os profissionais de enfermagem que atuam na Unidade de Terapia Intensiva Neonatal (UTIN) de um hospital universitário, na cidade de Cuiabá - MT. Consiste de um estudo do tipo descritivo qualitativo não participante, com coleta de dados de novembro de 2017 a fevereiro de 2018, por meio de observação, transcrição manual dos dados coletados e registro iconográfico. Os resultados evidenciaram que os trabalhadores estão expostos a riscos físicos, relacionados à radiação ionizante, a risco de acidentes, relacionados à falta de sinalização de segurança, a riscos ergonômicos relacionados à falta de acessibilidade e a riscos psicossociais, devido à carga excessiva de trabalho e stress. Propõese a implementação de programas de prevenção e conscientização de práticas seguras e formação contínua da equipe, a fim de conhecer as formas de adoecimento ocupacional, identificando suas causas e efeitos no ambiente de trabalho.
\end{abstract}

Palavras Chave: Saúde do Trabalhador. Unidade de Terapia Intensiva. Enfermagem.

\begin{abstract}
This study aimed to characterize the occupational risks to which nursing professionals working at the Neonatal Intensive Care Unit (NICU) of a university hospital, in the city of Cuiabá - MT, are exposed. It consists of a non - participatory qualitative descriptive study, with data collection was from November 2017 to February 2018, through observation, manual transcription of collected data and iconographic record. The results showed that workers are exposed to physical risks, related to ionizing radiation, to the risk of accidents, related to lack of safety signs, ergonomic risks related to lack of accessibility and psychosocial risks due to excessive workload and stress. It was proposed the implementation of prevention programs and awareness of safe practices and continuous training of the team, in order to know the forms of occupational illness, identifying their causes and effects in the work environment.
\end{abstract}

Keywords: Occupational Health. Intensive Care Unit. Nursing

\section{INTRODUÇÃO}

O trabalho é parte importante da vida de qualquer indivíduo, tendo papel fundamental na construção de sua identidade e interação com a sociedade, podendo ser considerado elemento de sua saúde. Porém, a organização do trabalho e o modo como ele é feito podem acarretar aspectos negativos, individualmente ou em grandes grupos, podendo gerar adoecimento e até, em algumas vezes, óbito. Desta forma, Cavalcante et al. (2006) afirmam que o ambiente de trabalho traz riscos para o indivíduo e as condições laborais são fundamentais para relação entre saúde e trabalho, sendo que a Saúde Ocupacional deve nortear as decisões tanto de empregados como de seus empregadores.

A organização do trabalho influencia diretamente na qualidade de vida, no desgaste e no adoecimento dos trabalhadores, bem como na saúde mental, devido às consequências de sofrimento psíquico que pode causar. Possui elevada importância, não somente para a compreensão e para intervenção em situações de trabalho que possam desencadear várias formas de sofrimento, mas, também, para a superação e transformação das organizações (DEJOURS, 1993b apud MARTINS, 2008). 
Para regulamentar os ambientes de trabalho e as atividades laborais sobre o tema da Segurança e Saúde Ocupacional, tem-se a Portaria no 3.214 (Brasil, 1978) do Ministério do Trabalho e Emprego, composta pelas 28 Normas Regulamentadoras (NR) relativas à Segurança e Medicina do Trabalho, totalizando, atualmente, 37 normas, às quais os empregadores e empregados devem obedecer visando a saúde e segurança nos ambientes laborais.

Dentre elas, a NR 05 e NR 09 (Brasil, 1978) descrevem os tipos de riscos ambientais, classificados em biológicos, químicos, físicos, ergonômicos e risco de acidentes. Ao se realizar levantamento de dados é possível verificar quais os fatores de risco, suas fontes e delimitação das medidas cabíveis para prevenção e correção dos riscos encontrados.

$\mathrm{Na}$ esfera hospitalar, ambiente de trabalho a que se refere este estudo, além da observância da NR 09, deve ser observada a norma específica de Segurança e Saúde no Trabalho em Serviços de Saúde, a NR 32 (Brasil, 1978). Estudos e estatísticas confirmaram que os profissionais da saúde estão sujeitos a maior número de riscos ocupacionais que outras categorias, devido às cargas física e mental que são demandados no cuidado de pacientes enfermos (CAVALCANTE et al., 2006).

Dentre todos os ambientes que compõem uma unidade de saúde, este estudo foca nos riscos ocupacionais em uma Unidade de Terapia Intensiva Neonatal (UTIN) de um hospital universitário, na cidade de Cuiabá - MT. A UTIN destina-se aos recém-nascidos (RN) gravemente enfermos com instabilidade hemodinâmica ou das funções vitais, bem como àqueles que apresentam alto risco de mortalidade e aos que requeiram vigilância, monitorização e ou tratamento intensivos (RUGOLLO, 2000 apud SARAIVA, 2004).

A referida unidade presta cuidado ininterrupto, por 24 horas a seus pacientes aos RN. Assim, faz-se necessário que o trabalhador também tenha condições adequadas no desempenho de suas atividades, melhorando sua produção e rendimento, pois seus pacientes dependem deste cuidado, a fim de que tenham boas condições de sobrevida (SARAIVA, 2004).

O interesse para o foco nessa tônica é justificado pela existência de múltiplos riscos que envolvem as atividades dos profissionais da saúde em UTIN, a constância de preocupações relacionadas às condições de trabalho nesses ambientes e às novas formas de análise englobando novos índices e moldes a serem observados nestes locais. Essa temática tem sido abordada por diversos autores, dentre eles Almeida, Beltrame e Salazar (2014) e Portela et al. (2021). Citam-se, também, estudos desenvolvidos em unidades de terapia não neonatal, como Santos et al. (2020), Nazario, Camponogara e Dias (2017) e Esin e Segin (2017).

Assim sendo, o objetivo deste estudo é verificar as condições físico-funcionais de uma Unidade de Terapia Intensiva Neonatal (UTIN) conforme as recomendações das Normas Regulamentadoras do Ministério do Trabalho e Emprego, Cartilha de Conforto Ambiental em Estabelecimentos Assistenciais de Saúde (Brasil, 2014). A contribuição do estudo se pauta em seu auxílio para que os riscos ocupacionais sejam reconhecidos, não só pelos trabalhadores, mas pelos gestores da unidade hospitalar, fornecendo subsídios para uma melhor qualificação da assistência prestada a seus pacientes.

\section{MATERIAIS E MÉTODO}

O presente estudo é do tipo descritivo qualitativo, desenvolvido na forma de observação não participante. O objeto de estudo é a Unidade de Terapia Intensiva Neonatal (UTIN) de um hospital público federal, na cidade de Cuiabá-MT, considerado centro de referência estadual, que atende grande demanda tanto da capital como de todo estado. Este é um hospital de referência para gestação de alto risco.

O período da coleta de dados foi de novembro de 2017 a fevereiro de 2018, por meio de observação, transcrição manual dos dados coletados e registro iconográfico. 
A partir da pesquisa de campo, junto à equipe que trabalha da UTIN, dados foram coletados por meio de anotações. Posteriormente, foram transcritos de forma digital, para que pudessem se tornar relatórios.

Os relatórios foram analisados, divididos e classificados levando em consideração os riscos e conforto ambiental. Os dados encontrados foram comparados a itens de avaliação das Normas Regulamentadoras do Ministério do Trabalho e Emprego, Cartilha de Conforto Ambiental em Estabelecimentos Assistenciais de Saúde (Brasil, 2014) e literatura específica.

Inicialmente, foi realizada visita técnica ao Hospital para verificar juntamente com outros membros da equipe de pesquisa, quais seriam os focos para desenvolvimento de estudos complementares dentro das possibilidades oferecidas. Os ambientes propostos para o estudo, dentro da Unidade de Saúde foram: cozinha, clínica de internação (a ser definida) e lavanderia.

Acompanhados de servidores do hospital, foram visitadas as clínicas: pediátrica, médica, cirúrgica, ginecologia e obstetrícia, assim como, a cozinha e o laboratório de análises clínicas. Não foi possível realizar visita técnica à lavanderia do hospital, visto que esse serviço é terceirizado.

A cada local visitado, alguns dos servidores que nos acompanhavam descreviam suscintamente as atividades ligadas ao objeto de pesquisa.

A princípio, as questões norteadoras foram àquelas relacionadas ao uso da água, devido a este estudo estar relacionado com a pesquisa denominada "Eficiência Hídrica e Desempenho Ambiental de Edifícios Destinados às Unidades de Saúde", submetida e aprovada pelo Comitê de Ética do referido hospital sob número 2.304.452. Este foi um critério de seleção do ambiente de estudo, a Unidade de Terapia Intensiva Neonatal (UTIN), pois, dentre todas as clínicas de internação visitadas na unidade hospitalar, nesta, o uso da água é mais relevante, uma vez que, nas outras clínicas, a água tem uso somente para banhos de leito e lavagem de mãos. Já na UTIN há uso da água tanto nos banhos como para umidificação e desinfecção das incubadoras.

Assim, foi realizado contato com a enfermeira-chefe da unidade para início da pesquisa de campo, com devida ciência e autorização da chefia.

Na UTIN, o ambiente principal conta com os leitos dos pacientes, dois locais para preparo de medicamentos, para prescrição e atividades administrativas (uma mesa e uma bancada), sala multiprofissional e expurgo. Estes foram os locais observados para coleta de dados quanto aos riscos ocupacionais.

Durante o acompanhamento das atividades que envolvem o uso da água, foi possível verificar parte das realizadas pelos profissionais da saúde quanto aos cuidados assistenciais a seus pacientes, seu comportamento no ambiente de trabalho e o ambiente em si. Também foi possível exercitar, com o olhar técnico as rotinas, sendo que, muitas das questões abordadas neste estudo, foram fruto das notas acerca das impressões obtidas do lugar. Dessas observações, foi possível se estabelecer relações entre o trabalho (atividades), os trabalhadores (pessoas) e o local de trabalho (ambiente), de forma que as análises abrangem os riscos ocupacionais e suas as interfaces com o conforto ambiental e a gestão organizacional.

A avaliação de riscos é feita com base nos dados colhidos durante visita do local de trabalho, fazendo levantamento dos perigos, situações ou eventos perigosos àqueles que estão expostos (Brasil, 1978). Perigos são considerados qualquer substância ou condição, com potencial de provocar danos ao funcionário ou patrimônio. E risco é definido como as consequências dos perigos existentes nas atividades e sua provável ocorrência (SOUZA, 2014). Posteriormente, associa-se às consequências do acidente uma probabilidade e gravidade para obter o risco de determinada atividade utilizando-se a matriz de gradação de risco, onde LEO significa Limite de Exposição Ocupacional (CARDELLA, 2007; SESI, 1994).

A combinação dos dados de probabilidade (Tabela 1) com os de gravidade (Tabela 2) compõe a denominada "Matriz de Riscos", conforme apresentado na Figura 1. 
Durante, L. C.; Marques, N. A. A. L. T.; et al; Riscos Ocupacionais Evidenciados em uma Unidade de Terapia intensiva Neonatal: Um Estudo de Caso. ES - Engineering and Science, 2021, 10:3.

Tabela 1 - Critérios do índice de probabilidade (P)

\begin{tabular}{|c|c|c|c|}
\hline \multirow{2}{*}{$\begin{array}{l}\text { Índice de } \\
\text { Probabilidade } \\
\text { (P) } \\
\end{array}$} & \multicolumn{3}{|c|}{ CRITÉRIO } \\
\hline & $\begin{array}{l}\text { Perfil de exposição } \\
\text { qualitativo }\end{array}$ & $\begin{array}{l}\text { Perfil de exposição } \\
\text { quantitativo }\end{array}$ & Fator de proteção \\
\hline $\begin{array}{l}\text { Altamente } \\
\text { improvável }\end{array}$ & $\begin{array}{l}\text { Exposição baixa: contato não } \\
\text { frequente com o agente ou } \\
\text { frequente a baixíssimas } \\
\text { concentrações/ intensidades. }\end{array}$ & $\begin{array}{l}\text { Exposição inferior a 10\% } \\
\text { do Limite de Exposição } \\
\text { Ocupacional (LEO). } \\
\text { E < 10\% LEO } \\
\text { Percentil } 95<0,1 \text { x LEO }\end{array}$ & $\begin{array}{l}\text { As medidas de controle } \\
\text { existentes são adequadas, } \\
\text { eficientes e há garantias de que } \\
\text { sejam mantidas em longo } \\
\text { prazo. }\end{array}$ \\
\hline $\begin{array}{l}2 \\
\text { Improvável }\end{array}$ & $\begin{array}{l}\text { Exposição moderada: } \\
\text { contato frequente com o } \\
\text { agente a baixas } \\
\text { concentrações/intensidades } \\
\text { ou contato não frequente a } \\
\text { altas concentrações ou } \\
\text { intensidades. }\end{array}$ & $\begin{array}{l}\text { Exposição estimada entre } \\
10 \% \text { e } 50 \% \text { do Limite de } \\
\text { Exposição Ocupacional } \\
\text { (LEO). } \\
10 \%<\text { E < = 50\% LEO } \\
\text { Percentil } 95 \text { entre } 0,1 \times \\
\text { LEO e } 0,5 \times \text { LEO }\end{array}$ & $\begin{array}{l}\text { As medidas de controle } \\
\text { existentes são adequadas e } \\
\text { eficientes, mas não há garantias } \\
\text { de que sejam mantidas em } \\
\text { longo prazo. }\end{array}$ \\
\hline $\begin{array}{l}3 \\
\text { Pouco provável }\end{array}$ & $\begin{array}{l}\text { Exposição significativa ou } \\
\text { importante: } \\
\text { contato frequente com o } \\
\text { agente a altas } \\
\text { concentrações/intensidades }\end{array}$ & $\begin{array}{l}\text { Exposição estimada entre } \\
50 \% \text { e } 100 \% \text { do Limite de } \\
\text { Exposição Ocupacional } \\
\text { (LEO). } \\
50 \%<\text { E <= } 100 \% \text { LEO } \\
\text { Percentil } 95 \text { entre } 0,5 \times \\
\text { LEO } 1,0 \times \text { LEO }\end{array}$ & $\begin{array}{l}\text { As medidas de controle } \\
\text { existentes são adequadas. mas } \\
\text { apresentando desvios ou } \\
\text { problemas significativos. A } \\
\text { eficiência é duvidosa e não há } \\
\text { garantias de manutenção } \\
\text { adequada. }\end{array}$ \\
\hline $\begin{array}{l}4 \\
\text { Provável }\end{array}$ & $\begin{array}{l}\text { Exposição excessiva: contato } \\
\text { frequente com o agente a } \\
\text { concentrações ou } \\
\text { intensidades elevadíssimas }\end{array}$ & $\begin{array}{l}\text { Exposição estimada acima } \\
\text { do Limite de Exposição } \\
\text { Ocupacional (LEO). } \\
\text { E > 100\% LEO } \\
\text { Percentil } 95>1,0 \text { x LEO }\end{array}$ & $\begin{array}{l}\text { Medidas de controle } \\
\text { inexistentes ou as medidas } \\
\text { existentes são } \\
\text { reconhecidamente inadequadas. }\end{array}$ \\
\hline
\end{tabular}

Fonte: Adaptado de MUCHAUSEN e DAMIANO (1998) e FIOCRUZ (1996).

Tabela 2 - Critérios do índice de gravidade $(\mathrm{G})$

\begin{tabular}{|c|c|c|}
\hline $\begin{array}{c}\text { Índice de } \\
\text { Gravidade do Dano } \\
(\mathbf{G})\end{array}$ & $\begin{array}{l}\text { Critério Utilizado } \\
\text { (Genérico) }\end{array}$ & Exemplos \\
\hline $\begin{array}{l}1 \\
\text { Reversível Leve }\end{array}$ & $\begin{array}{l}\text { Lesão ou doença leves, com } \\
\text { efeitos reversíveis levemente } \\
\text { prejudiciais. }\end{array}$ & $\begin{array}{l}\text { Ferimentos leves, irritações leves. que não implique } \\
\text { em afastamento não superior a } 15 \text { dias etc. }\end{array}$ \\
\hline $\begin{array}{l}2 \\
\text { Reversível Severo }\end{array}$ & $\begin{array}{l}\text { Lesão ou doença sérias, com } \\
\text { efeitos reversíveis severos e } \\
\text { prejudiciais. }\end{array}$ & $\begin{array}{l}\text { Irritações sérias, pneumoconiose não fibrogênica, } \\
\text { lesão reversível que implique em afastamento } \\
\text { superior a } 15 \text { dias, etc. }\end{array}$ \\
\hline $\begin{array}{l}3 \\
\text { Irreversível }\end{array}$ & $\begin{array}{l}\text { Lesão ou doença críticas, com } \\
\text { efeitos irreversíveis severos e } \\
\text { prejudiciais que podem limitar a } \\
\text { capacidade funcional. }\end{array}$ & $\begin{array}{l}\text { PAIR, danos ao sistema nervoso central (SNC), } \\
\text { lesões com sequelas que impliquem em afastamentos } \\
\text { de longa duração ou em limitações da capacidade } \\
\text { funcional. }\end{array}$ \\
\hline $\begin{array}{l}4 \\
\text { Fatal ou } \\
\text { Incapacitante }\end{array}$ & $\begin{array}{l}\text { Lesão ou doença incapacitante } \\
\text { ou fatal. }\end{array}$ & $\begin{array}{l}\text { Perda de membros ou órgãos que incapacitem } \\
\text { definitivamente para o trabalho, lesões múltiplas que } \\
\text { resultem em morte, doenças progressivas } \\
\text { potencialmente fatais tais como pneumoconiose } \\
\text { fibrogênica, câncer etc. }\end{array}$ \\
\hline
\end{tabular}

Fonte: Adaptado de MUCHAUSEN e DAMIANO (1998) e FIOCRUZ (1996). 
Figura 1 - Matriz de riscos

\begin{tabular}{|c|c|c|c|c|c|}
\hline GRAVIDADE & Trivial & Menor & Moderado & Maior & Desastre \\
PROBABIIDADE & 1 & 2 & 3 & 4 & 5 \\
\hline Remoto & $\mathrm{MB}$ & $\mathrm{MB}$ & $\mathrm{B}$ & $\mathrm{M}$ & $\mathrm{M}$ \\
1 & 2 & 3 & 4 & 5 & 6 \\
\hline Improvável & $\mathrm{MB}$ & $\mathrm{B}$ & $\mathrm{M}$ & $\mathrm{M}$ & $\mathrm{A}$ \\
2 & 3 & 4 & 5 & 6 & 7 \\
\hline Possível & $\mathrm{B}$ & $\mathrm{M}$ & $\mathrm{M}$ & $\mathrm{A}$ & $\mathrm{MA}$ \\
3 & 4 & 5 & 6 & 7 & 8 \\
\hline Provável & $\mathrm{M}$ & $\mathrm{M}$ & $\mathrm{A}$ & $\mathrm{MA}$ & $\mathrm{MA}$ \\
4 & 5 & 6 & 7 & 8 & 9 \\
\hline Quase certo & $\mathrm{M}$ & $\mathrm{A}$ & $\mathrm{MA}$ & $\mathrm{MA}$ & MA \\
5 & 6 & 7 & 8 & 9 & 10 \\
\hline
\end{tabular}

Fonte: Adaptação de MUCHAUSEN \& DAMIANO (1998).

Assim, é realizado o enquadramento para avaliação de acordo o valor encontrado na matriz de risco, sendo:

- Muito Baixo (MB) 2-3: aceitável, mas alertar os trabalhadores e monitorar a tarefa, revendo as medidas de controle para possíveis mudanças;

- Baixo (B) 4: tolerável, mas alertam para os riscos e melhorar as medidas de controle, sempre que possível;

- Médio (M) 5-6: inaceitável, rigorosas informações de alerta. As medidas de controle devem ser implementadas rapidamente;

- Alta (A) 7: totalmente inaceitável, requerem urgentemente medidas mais fortes de controle e sistema de trabalho seguros; e,

- Muito Alta (MA) 8-10: interromper as atividades imediatamente. Somente reiniciar trabalhos quando as medias preventivas estiverem implantadas.

\section{RESULTADOS/ DISCUSSÕES}

A UTIN se caracteriza como um ambiente de cuidado especial e intensivo ao recémnascido de alto risco. Para realização desse cuidado há atuação de equipe multidisciplinar contando com médicos, enfermeiros, técnicos de enfermagem, nutricionistas, fisioterapeutas e assistentes sociais, contando ainda com pessoal administrativo. A equipe de enfermagem é a que permanece por maior tempo no ambiente, prestando cuidado e assistência aos pacientes.

Com funcionamento ininterrupto, as jornadas de trabalho possuem a seguinte distribuição: dois turnos de seis horas (das 7 às 13h e das 13 às 19h) e plantão noturno de doze horas (19 as 07h). A população exposta aos riscos e que manipulam água no setor é composta por dois enfermeiros assistenciais e cinco técnicos no período diurno e por um enfermeiro assistencial, no período noturno.

Constatou-se que a água vinda do sistema de distribuição é utilizada somente para lavagem de mãos, desinfecção terminal das incubadoras e desinfecção geral da UTIN. A água utilizada para banho dos pacientes possui fonte diferenciada, geralmente de fonte mineral, como procedimento operacional padrão do setor para evitar infecção. Após este evento, a Comissão de Controle de Infecção Hospitalar (CCIH) juntamente com demais setores responsáveis pela clínica, modificaram as rotinas, para diminuir o risco de infecção na UTIN. 
Os riscos ocupacionais apontados seguiram os determinados pela Organização Mundial da Saúde (OMS), assim como as normas regulamentadoras do Ministério do Trabalho e Emprego, dividindo-se em biológicos, físicos, químicos, de acidentes ou mecânico e ergonômicos. Também foi adotada a parte subjetiva ligada ao risco, ainda não obrigatória na legislação brasileira, quanto a parte psicossocial.

Risco biológico é entendido como a probabilidade da exposição ocupacional a agentes biológicos; manuseio de materiais perfuro-cortantes; contato com secreções e fluídos do corpo do paciente; realização de procedimentos; contato com pessoas com doenças transmissíveis (NUNES et al., 2010 apud MEDEIROS et al., 2013). É uma das classes de riscos mais significativas no ambiente hospitalar, por tratar-se da contaminação tanto de pacientes e quanto de trabalhadores, aliados ao ambiente crítico e estressante que agrava a susceptibilidade a acidentes (BALTHAZAR et al., 2017). Observou-se que durante as atividades práticas da equipe de enfermagem da UTIN, existe a exposição a bactérias, vírus, microrganismos podendo causar doenças ou infecções. Mesmo que o paciente esteja em condições de isolamento (incubadora), sabe-se que existe o contato para realização de puncionamento de veias, coleta de material biológico para exames podendo causar ferimento pelo manuseio ou descarte incorreto de agulhas, dentre outros.

Como ações de controle e prevenção, verificou-se o uso de Equipamentos de Proteção Individual (EPI) e, também, caixas para descarte de material adequadas, seguindo as NR 6 e 32 (Figuras 02 e 03). Contudo, observou-se que alguns profissionais não utilizam todos os EPI necessários para realização dos procedimentos, algumas vezes pela experiência que já possuem devido ao tempo de trabalho e, outras, devido à pressa para realização de procedimentos, por conta do estado crítico em que o paciente se encontra.

Nos procedimentos padrões prestados aos pacientes, vê-se que o uso de EPI é constante. Porém, um item que deve ser levado em consideração é a lavagem das mãos. De acordo com Brasil (2007), a higienização das mãos é a medida individual mais simples e menos dispendiosa para prevenir a propagação das infecções relacionadas à assistência à saúde, tendo diversos modos de ser realizada, que vai desde higienização simples até a antissepsia cirúrgica das mãos. Na higienização simples das mãos, a técnica correta possui duração de 40 a 60 segundos. O que pode ser visto, é que a maioria de profissionais não obedece aos padrões estabelecidos para lavagem das mãos, tanto no uso das técnicas quanto no tempo gasto para fazer a higienização, mesmo estando à cartilha fixada logo acima do lavatório.

Ainda ligada à questão do risco biológico e relacionando-a com a possibilidade de ocorrência de acidentes com materiais perfuro-cortantes, percebeu-se que alguns trabalhadores utilizam calçados abertos, como sandálias e tamancos, fator esse que pode aumentar a probabilidade de ocorrência de ferimentos caso haja algum problema no manuseio do material.

Também contribuem para a exposição dos trabalhadores a riscos diversos, a presença dos pais, que na maioria das vezes não cumprem as rotinas de higiene necessárias para acesso e permanência na UTIN e questões atreladas a desinfecção terminal feita por terceirizados. Ambas, necessitam de uma gestão mais efetiva, uma vez que existem os protocolos e seu cumprimento deve ser cobrado por parte de todos os envolvidos.

Quanto aos pais, deveriam realizar higienização corretamente, fazendo a lavagem das mãos ou higienização com álcool e uso do avental privativo por cima da roupa. Notou-se que diversos pais não cumprem as regras básicas de lavagem das mãos e colocação dos aventais. Outra questão alarmante foi o uso de aparelhos celulares: os pais têm costume de pegar/tocar os bebês e, logo em seguida, manusear o aparelho ou vice-versa. Desta forma, o aparelho tornase fonte de agentes biológicos que podem trazer nova infecção e até mesmo agravar o estado dos RN, já que não é feita a higienização das mãos após o manuseio dos aparelhos. Sugere-se que seja criada alguma rotina quanto ao fato, para que tanto os pacientes, acompanhantes e 
trabalhadores possam estar assegurados dessa possível fonte de patógenos, aliado a treinamentos e reciclagem dos trabalhadores quanto às situações geradoras do risco.

Figura 02 - Folheto informativo quanto ao uso de EPI

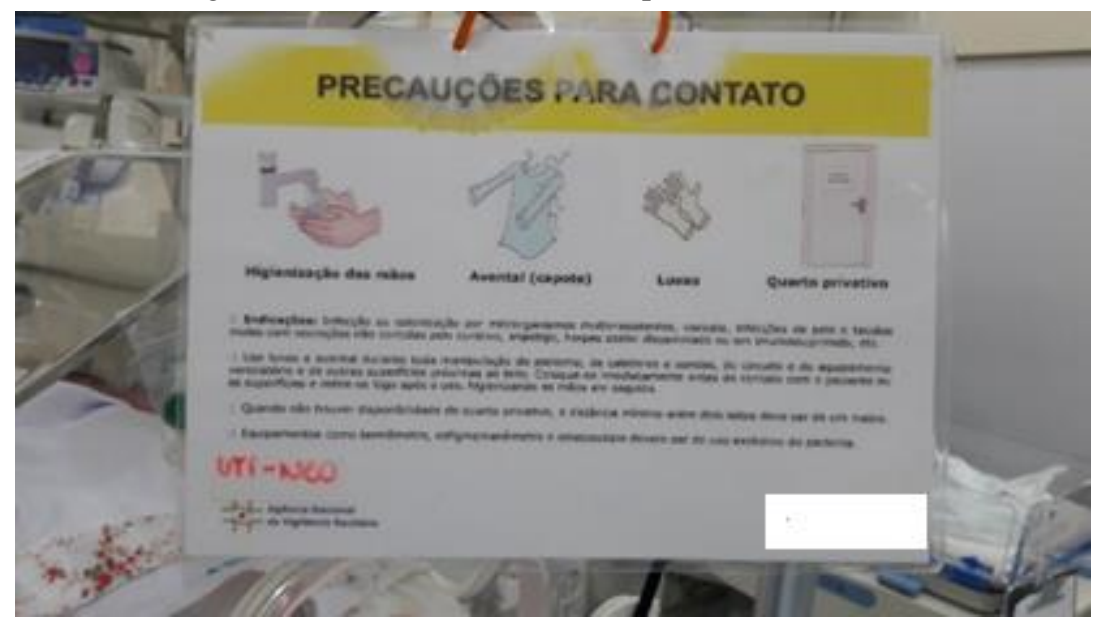

(2017)

Figura 03 - Caixa para descarte de perfuro-cortantes

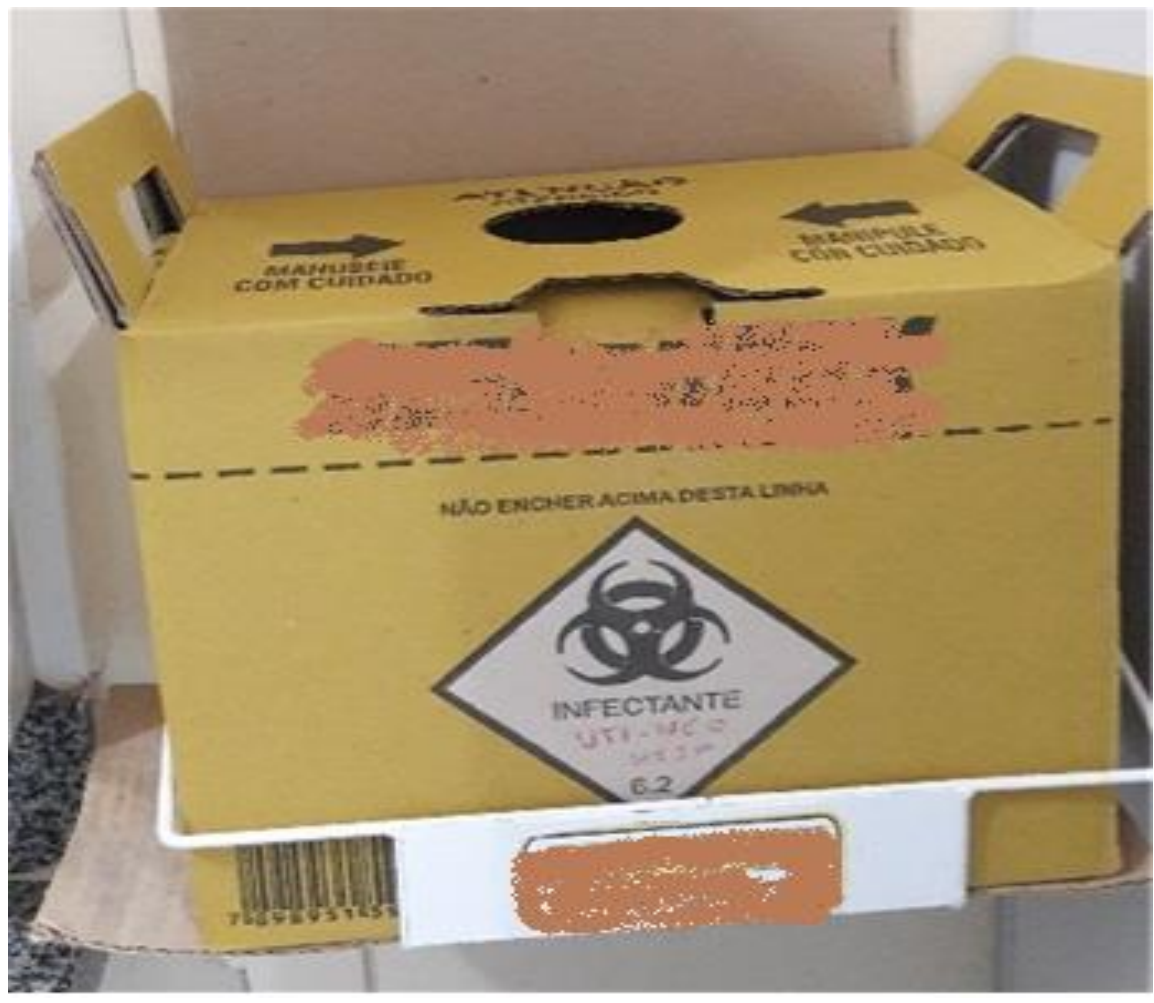

(2018)

Ainda entre os fatores de risco, outra situação ocorrida durante as observações foi a desinfecção terminal. A desinfecção terminal denominada "lavação" pelos servidores consiste na lavagem de piso, parede, teto e higienização de todas as superfícies. Uma equipe composta por quatro funcionários terceirizados realiza a limpeza, sendo que dois deles cuidam do chão e das paredes até meia altura (1,50 metros) e os outros dois cuidam do restante das paredes, altura maior que $1,50 \mathrm{~m}$, teto e todas as superfícies. O produto utilizado é o Incidin. No chão após a lavagem manual com esponjas, é passada enceradeira. Não ficou claro se a enceradeira é utilizada somente para limpeza da UTIN ou se também é utilizada em outros locais e, por isso, 
pode ser considerada vetor de agente biológicos vindo a causar problemas pelo seu uso. Nas paredes, até meia altura, é feita lavagem com esponjas e enxague com água da torneira. Dessa altura para cima, é usado um rodo especial onde são encaixadas esponjas embebidas em solução desinfetante para higienização das paredes. Por conta do pé direito alto, não é possível fazer higienização de toda extensão da parede assim como do teto (Figura 04). Recomenda-se que sejam disponibilizados instrumentos adequados para higienização correta e completa do ambiente.

Destaca-se que o processo de desinfecção das paredes em si não é objeto de estudo, porém, se não for bem realizado, pode expor a população de estudo a riscos biológicos, sendo, por isso, incluído nos levantamentos.

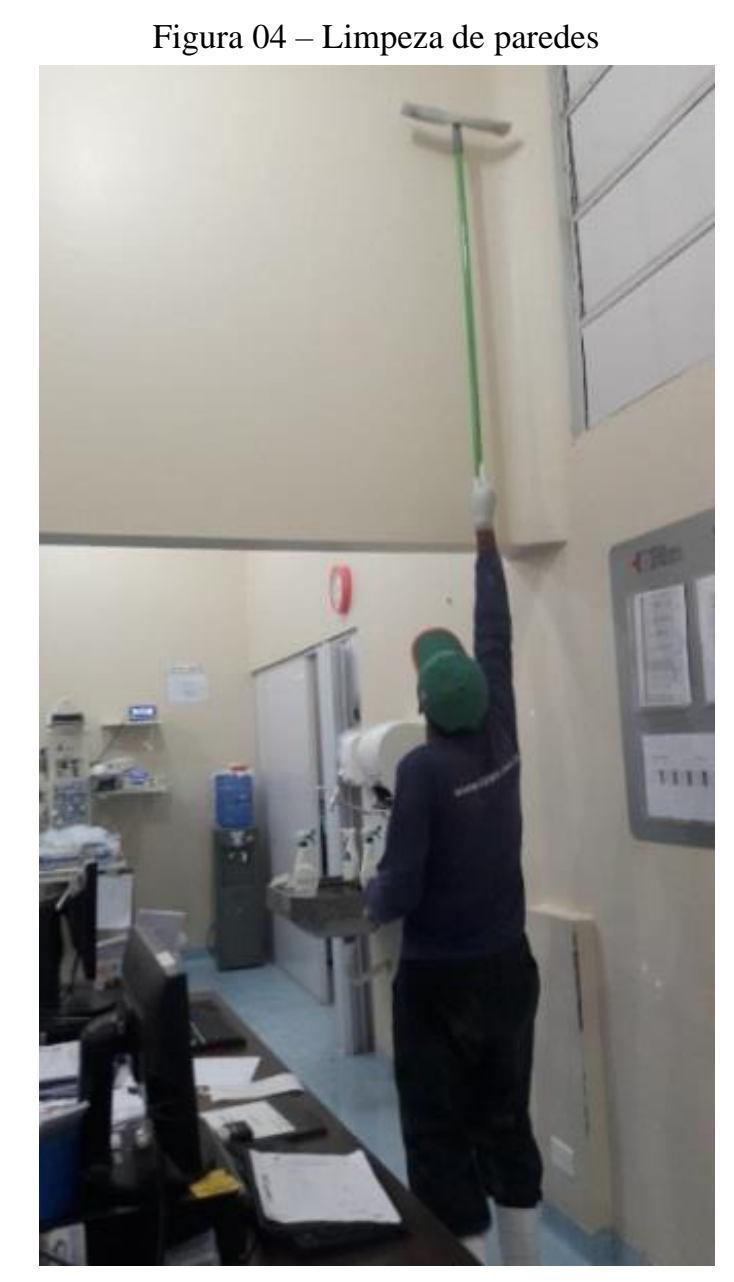

(2018)

A desinfecção de incubadoras é outro processo que envolve uso da água e pode ocorrer de acordo com três condicionantes: alta de paciente, óbito de paciente ou de sete em sete dias. O que acontecer primeiro, dentro das possibilidades, fará com que a desinfecção aconteça. As desinfecções são feitas pelas técnicas de enfermagem, na maioria das vezes. Consiste no desligamento de todo equipamento da parte elétrica, as partes móveis são retiradas e toda a superfície é higienizada por pano embebido solução desinfetante diluída em água. Após a higienização com pano úmido, é feita secagem da superfície com outro pano seco. Notou-se que durante a secagem alguns itens da parte interna das incubadoras são deixados sobre superfícies não esterilizadas, como por exemplo, cadeiras de uso geral, utilizadas pelas mães, podendo infectar as partes que acabaram de receber desinfecção terminal. Recomenda-se que 
as partes móveis retiradas sejam deixadas em superfície adequada, para evitar infecção acidental.

Quanto ao Risco de Acidente, sabe-se que está ligado a fatores ou situações que possam causar acidentes, como arranjo espacial inadequado; máquinas e equipamentos sem proteção; ferramentas ou utensílios inadequados; risco de choque (eletricidade); falta de sinalização (FELDMAN, 2008 apud MEDEIROS et al., 2013). No cuidado intensivo dos pacientes, seu estado crítico e o ambiente estressante também podem contribuir para sua ocorrência. De acordo com a literatura estudada, foi observado que esse tipo de acidente é bastante comum com profissionais da enfermagem, fazendo a notificação e encaminhamento para exames necessários conforme as determinações da Comissão de Controle de Infecção Hospitalar (SCCIH) de acordo com Leitão et al. (2008). No caso da UTIN o risco de acidente está por diversas vezes atrelado ao risco biológico, dada à frequência pela qual os procedimentos são realizados com materiais que podem causar ferimento.

Observa-se risco ligado a questão do arranjo espacial, que necessita melhorias, principalmente nas áreas de preparo de medicamento e de banhos. Ambos estão subdimensionados, fazendo com que os profissionais tenham que realizar seu trabalho em local bastante apertado e tendo de disputar espaço com outros colegas.

$\mathrm{Na}$ área onde os banhos são preparados existe uma bancada com cuba e prateleiras abaixo para guarda de objetos. A bancada é utilizada para esquentar a água utilizada nos banhos com auxílio de ebulidor, os materiais utilizados para os banhos ficam espalhados na bancada e alguns trabalhadores fazem uso da bancada para dar banho em seus pacientes. A constante passagem de pessoas na pequena circulação prejudica aqueles que estão fazendo uso da bancada para dar banho em seus pacientes, tendo de parar suas atividades para deixar o colega passar. Mostrouse preocupante a questão do aquecimento da água para os banhos, pois as tomadas disponíveis para acionar o ebulidor se encontram logo acima das bancadas, tendo que colocar o recipiente metálico próximo as bacias usadas para banho, podendo causar algum acidente, por conta do tamanho da bancada.

$\mathrm{Na}$ bancada ficam dispostos produtos para higienização, recipientes para aquecimento de água, bacias para banho, garrafão de água mineral, todos esses itens e a constante passagem de pessoas pela circulação elucidam outro fator de risco, pois enquanto o banho é dado, a passagem de pessoas acontece e, por consequência de algum esbarrão, um desses objetos pode cair, assim como a água dos banhos, causando escorregões e quedas, afetando tanto trabalhadores quanto pacientes (Figura 05). Devido ao pequeno espaço da bancada, outros profissionais dão banho usando a bacia, porém, o apoio é feito em banco altos posicionados ao lado dos leitos, podendo também causar algum acidente, queda e além de risco ergonômico (Figura 06).

Notou-se a necessidade de criação de espaço adequado para os banhos com criação de armário para armazenar os materiais usados na higienização, de forma a organizar melhor e evitar que os objetos fiquem amontoados; aumento do ambiente e adequação da bancada para abrigar melhor os profissionais que realizam a tarefa.

A acessibilidade, no caso da UTIN também se relaciona com risco de acidentes. Não se trata aqui apenas da acessibilidade para as mães que vão visitar seus RN em cadeiras de rodas, mas, principalmente, da circulação dos trabalhadores e a execução de suas atividades em alguns postos de trabalho, que se torna dificultosa, quando não impossível, devido ao pouco espaço para sua realização. Recomenda-se que seja feito rearranjo do layout interno, o mais breve possível, para que tanto trabalhadores como pacientes possam oferecer e receber melhor cuidado.

Conforme a NR-05, a CIPA deve elaborar Mapa de Riscos Ambientais de modo a garantir parte da conscientização, educação e orientação quanto aos acidentes de trabalho com todos os trabalhadores. Viu-se que no ambiente de estudo tal exigência não está sendo obedecida, uma vez que não foi encontrado o Mapa de Riscos da unidade. 
A sinalização de segurança se faz importante tanto para os trabalhadores do local quanto para os acompanhantes ou visitantes. Não se trata apenas de mapa de risco, fixado em local visível conforme estabelecido pela NR-05, mas de comunicação visual para visitantes e acompanhantes quanto às precauções que devem ser tomadas quanto a entrada e permanência de pessoas na UTIN. Para garantir cumprimento da legislação e assegurar a população local quanto aos riscos, é necessário que sejam providenciados materiais gráficos quanto aos riscos ocupacionais e ambientais. A sensibilização e treinamento da equipe que devem ser realizados de maneira constante.

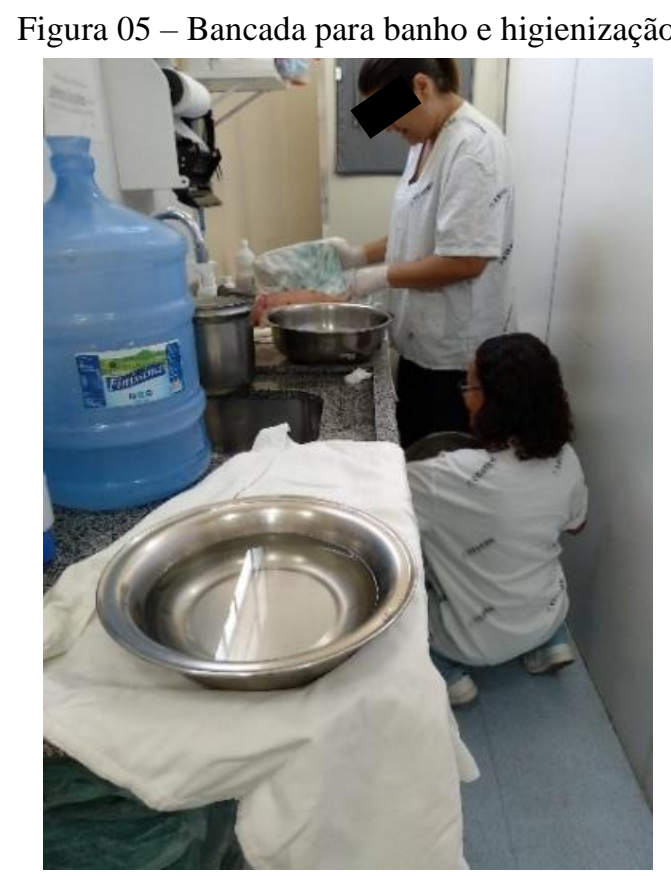

(2018)

Figura 06 - Banco utilizado para apoio nos banhos

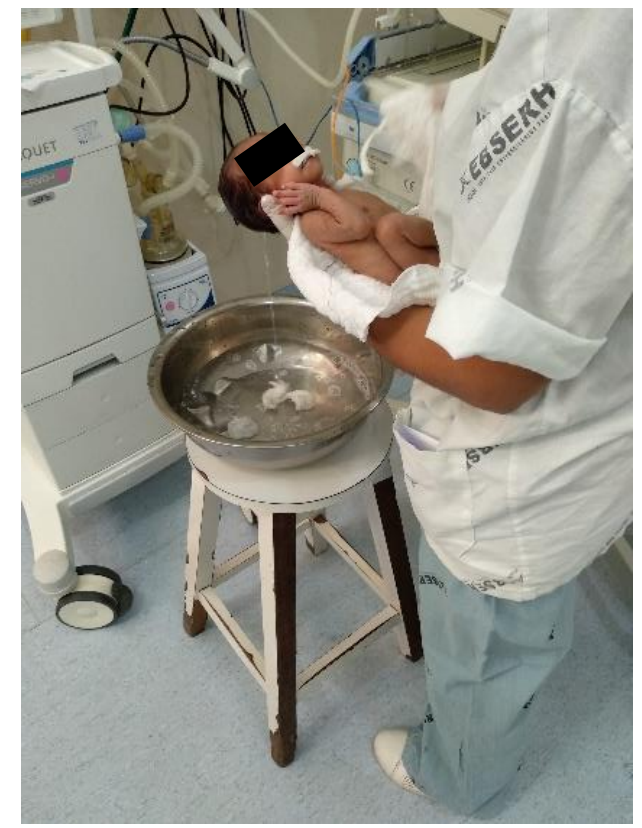

(2018) 
Em se tratando de Risco químico, na abordagem de Brasil (1978), essa categoria compreende risco de exposição a substâncias como, poeiras, gases e vapores que podem ser absorvidos pela pele, mucosas ou ingestão acidental de gotículas ou partículas, desenvolvendo efeitos irritantes diversos, principalmente nas vias respiratórias, com o que corrobora SCALDELAI et al., (2009). No ambiente de trabalho hospitalar, os riscos químicos podem estar relacionados à manipulação de alguns medicamentos, substâncias utilizadas em curativos, substâncias que podem ter efeito teratogênico e carcinogênico, bem como aquelas que podem causar dermatoses ocupacionais nos profissionais da equipe de enfermagem (SOUTO, 2005 apud LEITÃO et al., 2008).

Durante a observação foi possível verificar que os riscos químicos aos quais a equipe está sujeita, estão ligados, principalmente, à manipulação de drogas. O local utilizado para preparação de medicamentos também se encontra subdimensionado, deixando pouco espaço para que a equipe possa realizar suas tarefas de melhor forma. Além da bancada com cuba, temse prateleiras na parte de cima para separação de itens, armário alto de medicamentos, frigobar e, também, armário embutido abaixo da cuba com diversas gavetas. Cada paciente possui seus horários para receber medicação fazendo com que o espaço não fique ocupado todo tempo por grande número de pessoas. Porém quando os horários coincidem, a circulação de pessoas e a preparação de medicamentos podem ser prejudicados. Os riscos ligados à manipulação são minimizados por conta do uso de EPI, mas verificou-se que o uso não era constante na preparação, tendo sido registrado falta de uso de luvas e máscaras.

Outro fator observado, relaciona-se a exames em pacientes, e neste caso, durante a observação um dos pacientes passou por exame onde o contraste utilizado possuía efeito teratogênico. O contato dessa substância com mulheres grávidas ou mulheres que estão fazendo tratamento de fertilidade, pode afetar o feto causando má formação. A princípio não houve comunicação entre as equipes após a troca de turno acerca da situação que o paciente se encontrava, somente após certo tempo uma das enfermeiras responsáveis que estava no turno anterior comunicou a responsável pelo paciente, que todos fluídos expelidos pelo paciente possuíam toxicidade devido ao exame. Assim tiveram de fazer troca de responsável pelo leito, por conta da situação da técnica de enfermagem, que se encontrava fazendo tratamento de fertilidade.

Produtos utilizados para limpeza e higienização também podem causar erupções cutâneas e dermatites em pessoas com hipersensibilidade ao produto. Na UTIN os trabalhadores utilizam o desinfetante diluído em água, cujo princípio ativo é a glucoprotamina, e o fazem com uso de luvas descartáveis. $\mathrm{Na}$ oportunidade da visita não foi constatado que os funcionários responsáveis pela limpeza tivessem qualquer tipo de reação ao produto.

Com objetivo de sanar os problemas encontrados, deve-se realizar melhoria no local onde os medicamentos são preparados, deverá ser realizado treinamento e reciclagem com a equipe quanto ao uso de EPI como medidas de biossegurança e a comunicação entre as equipes mostrase essencial, para evitar que funcionários sejam intoxicados por medicamentos ou produtos hospitalares.

Na esfera dos Riscos físicos, também na abordagem de Brasil (1978), por definição, consistem em formas de energia representadas por ruído, vibração, temperaturas (frio, calor), pressões anormais, radiação não ionizante, radiação ionizante, umidade, luminosidade, infra e ultrassom (VENDRAME, 2005).

Constatou-se que os principais riscos físicos que acometem aos profissionais da UTIN estão associados a ruídos, radiação ionizante, radiação não ionizantes, frio e calor. Sabe-se que a exposição a ruídos por longo período, mesmo sem intensidade pode causar perda auditiva. De acordo com Vivan, Lins e Durante (2012), na UTIN, os níveis médios de pressão sonora ultrapassam os estabelecidos para o ambiente do tipo Berçário, cujo ruído estabelecido é de 35$45 \mathrm{~dB}(\mathrm{~A})$, devido ao número de equipamentos ligados na unidade e a quantidade de pessoas 
que prestam serviço. Muitas vezes, o portador da lesão auditiva não percebe de imediato. Porém, tais incapacidades podem influenciar sua vida profissional trazendo maior risco de acidentes, assim como sua vida pessoal.

Como fontes de radiação não-ionizante tem-se o aparelho de fototerapia, luz visível (iluminação artificial) e telefone celular, sendo que os danos causados por tais radiações são notados com o tempo e dependem da intensidade de exposição. Os aparelhos de fototerapia são utilizados para tratamento dos pacientes, sendo acionados ocasionalmente, de acordo com a necessidade. No entanto, a luz visível e o telefone celular estão presentes frequentemente durante o cotidiano dos pacientes e trabalhadores, sendo mais difícil a elucidação de medidas que diminuam o contato. Sabe-se que os efeitos são diversos, podendo provocar distúrbios do sono e aumento da pressão sanguínea (DIAS et al, 2002; DIAS et al, 2009).

A radiação ionizante está diretamente ligada à realização de exame com o aparelho raio $\mathrm{X}$. Durante o acompanhamento das atividades, quando da realização de exame radiológico houve alguns casos de transferência de leito sem prévia comunicação e a não-comunicação de realização do exame, fazendo com que alguns trabalhadores ficassem expostos a radiação sem necessidade. Os efeitos da radiação ionizante no corpo se manifestam de acordo com o tempo e frequência de exposição a qual o trabalhador, não sendo sentidas de imediato suas consequências, podendo causar efeitos cancerígenos e teratogênicos.

Juntamente com a solicitação do exame, seguem os dados do paciente e o técnico se encaminha até a UTI com o aparelho de raio X. Em alguns casos, foi observado que o paciente havia sido transferido de leito e não havia comunicado o técnico radiologista, fazendo com que outro paciente fosse exposto a radiação ionizante sem necessidade. Antes da realização do exame seria necessário que o técnico comunicasse a equipe de enfermagem confirmasse o paciente e o exame de raio $\mathrm{X}$ e tipo de exame a ser realizado na unidade, solicitando a saída das pessoas do ambiente, ou então, oferecendo a proteção necessária, porém não foi observada a presença de avental de chumbo, conforme prevê a NR-32 (Brasil, 1978), no local durante o período de coleta de dados.

Recomenda-se que seja implementado um programa de monitoramento da exposição dos trabalhadores às radiações, obedecendo às normas estabelecidas pela Comissão Internacional de Proteção contra Radiações (SOUTO, 2005 apud LEITÃO et al., 2008) e NR-32 (Brasil, 1978).

Com relação ao ambiente térmico, observou-se que a UTIN possui dois condicionadores de ar, onde cada um atende cinco leitos. Mesmo com o controle de temperatura dos RN feito pelas incubadoras, algumas portinholas ficam abertas para fazer circulação interna do ar como forma de manter a temperatura dos pacientes. A temperatura dos condicionadores de ar varia entre $25^{\circ}$ a $27^{\circ} \mathrm{C}$, e por diversas vezes, de acordo com o estado dos pacientes os aparelhos são ligados e desligados para que seja mantida a estabilidade termodinâmica. Quanto ao bem-estar do paciente, tal postura demonstra seu atendimento parcial, visto que alguns pacientes estão isolados em incubadoras e outros em berços térmicos abertos. Porém, durante a observação da execução das atividades laborais, foi verificado que a população da amostra, por algumas vezes, demonstrou reações de incômodo em relação à temperatura, observadas por meio de seus gestos corporais, tais como abanar as mãos próximas à face e enxugar suor da face, o que permite inferir que o ambiente térmico apresente um grau de desconforto por calor, embora ao mesmo não tenha sido quantificado.

Segundo Brasil (2014), o parâmetro recomendado de temperatura de acordo com o usuário de centros obstétricos com foco em neonatos, pela recomendação da Sociedade Brasileira de Pediatria (SBP) deve ser de $26^{\circ} \mathrm{C}$. Recomenda-se que a temperatura dos condicionadores de ar siga tal premissa, de modo a tornar-se confortável tanto para os servidores quanto para pacientes. 
Os Riscos ergonômicos, por sua vez, referem-se à falta de adaptação do trabalho ao homem, ou seja, aquele ambiente de trabalho que não segue os fatores antropométricos causando sobrecarga na estrutura musculoesquelética como exigência de posturas inadequadas, esforço físico intenso, repetitividade, trabalho em turno diurno e noturno, jornada de trabalho prolongada (MEDEIROS et al., 2013).

Entre os profissionais da UTIN em estudo, verificou-se postura inadequada, movimentos repetitivos, falta de acessibilidade. $\mathrm{Na}$ postura inadequada se manifestam: mobiliário inadequado e trabalho em pé. No mobiliário, deve-se prever consideração antropométrica inerente ao usuário e suas dimensões, conforme disposta na Nota Técnica 060 (MTE, 2001) e em Brasil (2014), que apresentam a abordagem ergonômica relacionada ao mobiliário, indicando as posturas que deverão ser adotadas nos postos de trabalho

Por se tratar de ambiente frequentado por grupos de pessoas com estaturas diferentes, a recomendação do MTE trata sobre a regulagem para apoio de braços, altura da superfície dos assentos, encosto de costas e da cabeça. No ambiente de estudo a altura das estações de trabalho estão obedecendo ao padrão, variando de 73 a $75 \mathrm{~cm}$, mas, as cadeiras não possuem assentos, apoio e altura ajustáveis podendo causar lesões musculoesqueléticas aos usuários (Figura 07).

Quanto ao trabalho em pé, foi observado que atrelado ao trabalho na posição em pé, temse os movimentos repetitivos durante a tarefa de cuidado dos pacientes. Como exemplo, a passagem de sonda, que deve ser realizada em pé por conta da altura da incubadora, tendo ainda os profissionais que se debruçarem sobre o paciente para ter melhor visão de suas veias diminutas, ao realizarem punções venosas.

Os períodos onde os trabalhadores conseguem ficar sentados para descanso são poucos e durante essas ocasiões, caso todos queiram sentar-se não terão assentos suficientes para todos. Quanto à acessibilidade, foram abordados seus aspectos nos riscos mecânicos (de acidentes) que consistem na falta de espaço necessário para realização de tarefas como banhos, preparo de medicamentos e circulação.

Sugere-se que sejam substituídos os móveis para seguir os padrões estabelecidos na norma técnica do MTE, de acordo com Figura 08 para adequação das estações de trabalho. No trabalho de pé será necessário que ao sentirem cansaço ou necessidade de pausas, que sejam feitas. Recomenda-se também que seja feita ginástica laboral para relaxamento e alongamento muscular.

Figura 07 - Postos de Trabalho UTIN

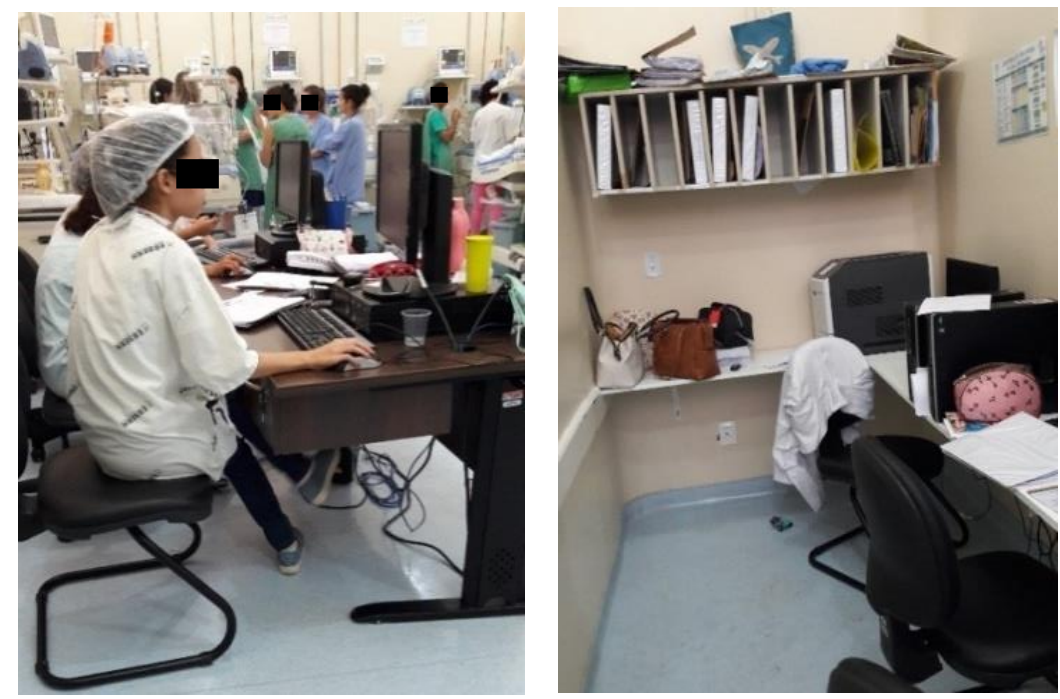

(2018) 


\section{Figura 08 - Recomendações de altura para trabalho sentado em relação a} monitores de computador

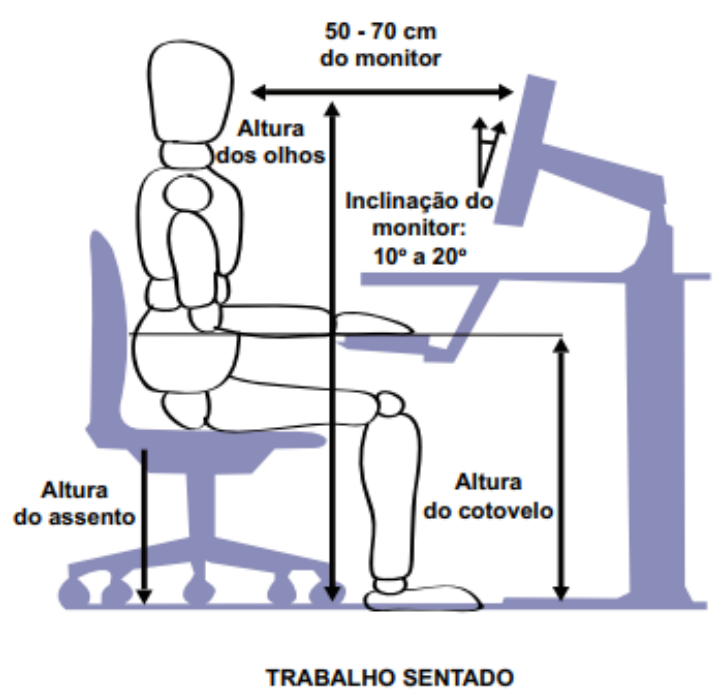

Fonte: Brasil (2014)

Risco psicossocial diz respeito aqueles resultantes das relações e organização do trabalho desfavorável ao trabalhador e que produzem sobrecarga psíquica assim como pressão da chefia, assédio moral, stress, acumulo de tarefas, tarefas perigosas, grau de atenção exigido, longas jornadas de trabalho, dentre outros (RIBEIRO, 2008 apud MEDEIROS et al., 2013). O risco psicossocial é um fator subjetivo, explorado e conhecido pelas agências reguladoras ligadas ao trabalho no exterior, mas que ainda não possui regulamentação do MTE.

Constatou-se que na UTIN as situações de riscos psicossociais entre os profissionais foram carga excessiva de trabalho e stress. A carga de trabalho dupla ou tripla, da qual diversos profissionais da enfermagem possuem juntamente com distúrbios do sono, cansaço, sobrecarga de atividades e responsabilidade aliados ao ritmo frenético de uma unidade de terapia intensiva contribuem consideravelmente para o desgaste psicológico no ambiente hospitalar. As consequências podem variar se fatores psicológicos como ansiedade, depressão, frustração, uso de ansiolíticos, podendo causar a síndrome de Burnout até consequências físicas como hipertensão, diabetes, taquicardia e alteração de fluxo menstrual (SHOJI et al., 2016 apud BALTHAZAR et al., 2017).

O stress também está ligado à duração de jornada de trabalho, podendo ser uma de suas consequências e afetando o desempenho profissional, podendo causar falhas de percepção e dificuldade de concentração, segundo Leitão et al (2017). São fatores relacionados ao stress: sobrecarga de atividades, ambiente de trabalho tenso, rotina de trabalha intensa, riscos, carga de trabalho elevada, tarefas complexas, rápida tomada de decisões, choro constante de pacientes. Chegou-se à conclusão relevante quanto a algumas das informações colhidas, pois diversos profissionais relatam ter stress como parte da profissão, não relatando à chefia fatores ligados a ele, que afetam sua rotina de trabalho, e consequentemente seu estado emocional e físico, arriscando-se à ocorrência de acidentes e erros relacionados ao trabalho.

A maior participação de gestores nos processos que envolvem o cuidado com os pacientes e trabalhadores, melhor investimento da infraestrutura, valorização do trabalho dos profissionais e humanização são recomendações para atenuar os fatores psicossociais que envolvem serviços hospitalares, segundo Balthazar (2017).

Quanto ao enfrentamento de riscos psicossociais, não há norteadores nas Normas Regulamentadoras, o que nos leva a refletir que muitas questões precisam ser revistas para que 
as instituições que regulamentam o trabalho possam registrar tais casos e tenham ferramentas capazes de combatê-lo, possibilitando que os trabalhadores tenham melhor qualidade de vida e consequentemente mais saúde.

Com os dados oriundos das observações no local da pesquisa foi possível realizar avaliação qualitativa dos riscos, verificando o controle existente, sua aplicabilidade, a forma como está afetando os trabalhadores e as sugestões de algumas estratégias de ação para sanar os pontos críticos, de modo que o risco possa se tornar aceitável, dentro das possibilidades, como demonstram os Quadros 1 a 6, a seguir.

De acordo com o exposto nas tabelas, vemos que as situações que possuem categoria de risco menor, são aquelas ligadas aos acidentes mais conhecidos dentro da esfera hospitalar, sendo riscos biológicos com a possibilidade e transmissão de doença por contato, pelo sangue e ar.

Nos fatores de risco médio temos as seguintes situações: ferimentos com perfurocortantes; exposição a agentes químicos; queda, escorregão, tropeços, objetos soltos, recipientes como fonte geradora de calor; ruído; radiação não-ionizante; calor e frio; postura inadequada e movimentos repetitivos.

Quadro 01 - Avaliação Preliminar de Riscos Biológicos

\begin{tabular}{|c|c|c|c|}
\hline PERIGOS & PROVÁVEIS CAUSAS & DANO & RECOMENDAÇÕES \\
\hline $\begin{array}{l}\text { Transmissão de Doenças } \\
\text { por contato, pelo sangue, } \\
\text { pelo ar } \\
\text { Probabilidade: } 1 \\
\text { Gravidade: } 3 \\
\text { Categoria de Risco: } 4 \\
\text { Prioridade: Baixa }\end{array}$ & $\begin{array}{l}\text { Contato direto com paciente enfermo } \\
\text { com tuberculose, hepatite ou HIV e, } \\
\text { nesse caso, contato com o agente } \\
\text { patogênicos, como por exemplo, } \\
\text { Pseudomonas, Legionella. Durante a } \\
\text { manipulação o paciente ou fazendo } \\
\text { procedimentos o profissional pode ter } \\
\text { contato pelo ar ou acidentalmente pelo } \\
\text { sangue e se infectar. }\end{array}$ & $\begin{array}{l}\text { Infecção por } \\
\text { Agentes } \\
\text { Patogênicos }\end{array}$ & $\begin{array}{l}\text { Conscientização dos } \\
\text { trabalhadores, continuar } \\
\text { com medidas preventivas } \\
\text { usando EPC e EPI }\end{array}$ \\
\hline
\end{tabular}

Quadro 02 - Avaliação Preliminar de Risco de Acidentes

\begin{tabular}{|c|c|c|c|}
\hline PERIGOS & PROVÁVEIS CAUSAS & DANO & RECOMENDAÇÕES \\
\hline $\begin{array}{l}\text { Ferimentos com perfuro } \\
\text { cortantes } \\
\text { Probabilidade: } 3 \\
\text { Gravidade: } 2 \\
\text { Categoria de Risco: } 5 \\
\text { Prioridade: Média }\end{array}$ & $\begin{array}{l}\text { Durante preparação, realização ou } \\
\text { descarte dos equipamentos utilizados } \\
\text { para fazer procedimentos, podem se } \\
\text { furar, cortar. }\end{array}$ & $\begin{array}{l}\text { Possível } \\
\text { Infecção por } \\
\text { Agentes } \\
\text { Patogênicos }\end{array}$ & $\begin{array}{l}\text { Treinamento, atenção as } \\
\text { tarefas realizadas, respeitar } \\
\text { o limite de preenchimento } \\
\text { dos recipientes que } \\
\text { recebem equipamento. }\end{array}$ \\
\hline $\begin{array}{l}\text { Queda, escorregão, } \\
\text { tropeços, objetos soltos, } \\
\text { recipientes como fonte } \\
\text { geradora de calor } \\
\text { Probabilidade: } 3 \\
\text { Gravidade: } 3 \\
\text { Categoria de Risco: } 6 \\
\text { Prioridade: Média }\end{array}$ & $\begin{array}{l}\text { Piso úmido ou molhado. Pouco espaço } \\
\text { para circulação. Objetos amontoados. } \\
\text { Preparo da água para banho, usando } \\
\text { recipiente metálico e ebulidor. }\end{array}$ & $\begin{array}{l}\text { Machucados, } \\
\text { lesões, } \\
\text { fraturas, } \\
\text { escoriações, } \\
\text { queimaduras }\end{array}$ & $\begin{array}{l}\text { Manutenção de instalações } \\
\text { hidráulicas, melhoria da } \\
\text { distribuição interna de } \\
\text { layout, instalação de novos } \\
\text { armários para guardar } \\
\text { objetos de acordo com seu } \\
\text { uso. }\end{array}$ \\
\hline $\begin{array}{l}\text { Falta de sinalização de } \\
\text { segurança } \\
\text { Probabilidade: } 4 \\
\text { Gravidade: } 3 \\
\text { Categoria de Risco: } 7 \\
\text { Prioridade: Média }\end{array}$ & $\begin{array}{l}\text { Poucos ou nenhuns avisos quanto às } \\
\text { normas de segurança; não foi } \\
\text { encontrado Mapa de Riscos } \\
\text { Ambientais. }\end{array}$ & Acidentes & $\begin{array}{l}\text { Providenciar material de } \\
\text { comunicação visual quanto } \\
\text { aos riscos. }\end{array}$ \\
\hline
\end{tabular}


Quadro 03 - Avaliação Preliminar de Riscos Químicos

\begin{tabular}{|c|c|c|c|}
\hline PERIGOS & PROVÁVEIS CAUSAS & DANO & RECOMENDAÇÕES \\
\hline $\begin{array}{l}\text { Exposição a agentes } \\
\text { químicos } \\
\text { Probabilidade: } 3 \\
\text { Gravidade: } 2 \\
\text { Categoria de Risco: } 5 \\
\text { Prioridade: Média }\end{array}$ & $\begin{array}{l}\text { Equipe de Enfermagem - Exposição a } \\
\text { substâncias químicas utilizadas em } \\
\text { ambientes de cuidados de saúde por } \\
\text { diversos motivos, por exemplo, para } \\
\text { tratamento de doentes (medicamentos } \\
\text { e agentes anestésicos). Contato com } \\
\text { talco das luvas de procedimento. Em } \\
\text { algumas situações, as drogas ou outros } \\
\text { medicamentos utilizados no tratamento } \\
\text { de doentes podem ter efeitos } \\
\text { inesperado. Equipe de Limpeza - } \\
\text { exposição ao limpar, desinfetar e } \\
\text { esterilizar superfícies e materiais } \\
\text { (detergentes/ desinfetantes). Pode } \\
\text { haver inalação de gases, vapores, } \\
\text { poeiras; contato com substância } \\
\text { líquida. }\end{array}$ & $\begin{array}{l}\text { Podendo } \\
\text { causar } \\
\text { sensibilidade, } \\
\text { irritação, } \\
\text { alergias, } \\
\text { danos físicos } \\
\text { e problemas } \\
\text { de saúde. O } \\
\text { dano vai } \\
\text { depender da } \\
\text { frequência e } \\
\text { quantidade } \\
\text { ao qual o } \\
\text { trabalhador } \\
\text { estiver } \\
\text { exposto. }\end{array}$ & $\begin{array}{l}\text { Treinamento, reciclagem, } \\
\text { comunicar a responsável do } \\
\text { setor quanto à } \\
\text { sensibilização a } \\
\text { determinado tipo de } \\
\text { substância para que sejam } \\
\text { tomadas providências } \\
\text { cabíveis. }\end{array}$ \\
\hline
\end{tabular}

Quadro 04- Avaliação Preliminar de Riscos Físicos

\begin{tabular}{|c|c|c|c|}
\hline PERIGOS & $\begin{array}{c}\text { PROVÁVEIS } \\
\text { CAUSAS }\end{array}$ & DANO & RECOMENDAÇÕES \\
\hline $\begin{array}{l}\text { Ruído } \\
\text { Probabilidade: } 3 \\
\text { Gravidade: } 3 \\
\text { Categoria de Risco: } 6 \\
\text { Prioridade: Média }\end{array}$ & $\begin{array}{l}\text { Equipamento de } \\
\text { monitoramento dos } \\
\text { pacientes. }\end{array}$ & $\begin{array}{l}\text { Dores de Cabeça, náusea, } \\
\text { perda de audição, zumbido, } \\
\text { ansiedade e insônia. }\end{array}$ & $\begin{array}{l}\text { Estabelecer intervalos com } \\
\text { saída do ambiente para } \\
\text { diminuir exposição ao } \\
\text { agente. }\end{array}$ \\
\hline $\begin{array}{l}\text { Radiação Ionizante } \\
\text { Probabilidade: } 5 \\
\text { Gravidade: } 4 \\
\text { Categoria de Risco: } 9 \\
\text { Prioridade: Muito Alta }\end{array}$ & $\begin{array}{l}\text { Exposição a Raio X. } \\
\text { Contato direto com } \\
\text { paciente que tenha } \\
\text { feito exame ou } \\
\text { ingerido medicamento } \\
\text { tóxico e/ou } \\
\text { teratogênico. }\end{array}$ & $\begin{array}{l}\text { Seus efeitos dependerão do } \\
\text { tempo de exposição e qual } \\
\text { agente em contato. Podendo } \\
\text { causar cefaleia, vertigem, } \\
\text { debilidade, sintomas } \\
\text { gastrointestinais, sintomas } \\
\text { cardiovasculares, alterações } \\
\text { de quadro sanguíneo, } \\
\text { perturbações psíquicas, } \\
\text { baixas defesas orgânicas. }\end{array}$ & $\begin{array}{l}\text { Comunicação interna } \\
\text { quanto a realização de } \\
\text { exames, avisando aos } \\
\text { colegas que o exame será } \\
\text { realizado e providenciando } \\
\text { proteção necessária a quem } \\
\text { não puder sair do local. }\end{array}$ \\
\hline $\begin{array}{l}\text { Radiação Não-Ionizante } \\
\text { Probabilidade: } 3 \\
\text { Gravidade: } 2 \\
\text { Categoria de Risco: } 5 \\
\text { Prioridade: Média } \\
\end{array}$ & $\begin{array}{l}\text { Aparelho de } \\
\text { Fototerapia (RN's), luz } \\
\text { visível, telefone } \\
\text { celular }\end{array}$ & $\begin{array}{l}\text { Pode causar mudanças na } \\
\text { velocidade de reação das } \\
\text { ondas cerebrais durante o } \\
\text { sono, mas não quer dizer } \\
\text { perda de sono. }\end{array}$ & $\begin{array}{l}\text { Estabelecer intervalos com } \\
\text { saída do ambiente para } \\
\text { diminuir exposição ao } \\
\text { agente. }\end{array}$ \\
\hline $\begin{array}{l}\text { Calor/Frio } \\
\text { Probabilidade: } 3 \\
\text { Gravidade: } 2 \\
\text { Categoria de Risco: } 5 \\
\text { Prioridade: Média } \\
\end{array}$ & Desconforto térmico & $\begin{array}{l}\text { Por não serem questões } \\
\text { extremas, podem ser } \\
\text { considerados como } \\
\text { causadores de fadiga física e } \\
\text { risco de acidentes }\end{array}$ & $\begin{array}{l}\text { Estabelecer temperatura } \\
\text { padrão para ser obedecida } \\
\text { de modo que não ofereça } \\
\text { riscos aos pacientes } \\
\text { também }\end{array}$ \\
\hline
\end{tabular}

Quanto aos fatores de risco classificados com altos ou muito altos encontram-se: Radiação Ionizante; Falta de sinalização de segurança; Acessibilidade; Carga Excessiva de Trabalho; Stress.

No enfrentamento dos riscos previstos da legislação pertinente, percebe-se que podem ser controlados e evitados no ambiente de trabalho com a utilização dos itens previstos nas normas regulamentadoras como técnicas e ferramentas de gestão para segurança do ambiente e do trabalhador, favorecendo a prevenção de acidentes. 
Quadro 05 - Avaliação Preliminar de Riscos Ergonômicos

\begin{tabular}{|c|c|c|c|}
\hline PERIGOS & $\begin{array}{l}\text { PROVÁVEIS } \\
\text { CAUSAS } \\
\end{array}$ & DANO & RECOMENDAÇÕES \\
\hline $\begin{array}{l}\text { Postura Inadequada } \\
\text { Probabilidade: } 3 \\
\text { Gravidade: } 3 \\
\text { Categoria de Risco: } 6 \\
\text { Prioridade: Média }\end{array}$ & $\begin{array}{l}\text { Mobiliário sub ou } \\
\text { superdimensionado, } \\
\text { mobiliário não } \\
\text { condizente com o local } \\
\text { em que foi implantado, } \\
\text { necessitando ajustes. } \\
\text { Trabalho em pé. }\end{array}$ & $\begin{array}{l}\text { Pode causar } \\
\text { comprometimento no sistema } \\
\text { musculoesquelético, podendo } \\
\text { surgir lesões e inflamações. } \\
\text { Como exemplo: tendinites, } \\
\text { bursites, lombalgias e dores } \\
\text { crônicas na coluna. }\end{array}$ & $\begin{array}{l}\text { Redistribuição interna de } \\
\text { leioute, melhoria das } \\
\text { estações de trabalho, troca } \\
\text { de mobiliário. }\end{array}$ \\
\hline $\begin{array}{l}\text { Movimentos Repetitivos } \\
\text { Probabilidade: } 3 \\
\text { Gravidade: } 3 \\
\text { Categoria de Risco: } 6 \\
\text { Prioridade: Média }\end{array}$ & $\begin{array}{l}\text { Monitoramento dos } \\
\text { pacientes, trabalhos } \\
\text { administrativos }\end{array}$ & $\begin{array}{l}\text { Pode causar } \\
\text { comprometimento no sistema } \\
\text { musculoesquelético, podendo } \\
\text { surgir lesões e inflamações. } \\
\text { Como exemplo: tendinites, } \\
\text { bursites, lombalgias, dores } \\
\text { crônicas na coluna, Lesões } \\
\text { por Esforço Repetitivo } \\
\text { (LER), lesões articulares. }\end{array}$ & $\begin{array}{l}\text { Ginástica Laboral, } \\
\text { intervalos. }\end{array}$ \\
\hline $\begin{array}{l}\text { Acessibilidade } \\
\text { Probabilidade: } 3 \\
\text { Gravidade: } 3 \\
\text { Categoria de Risco: } 6 \\
\text { Prioridade: Média }\end{array}$ & $\begin{array}{l}\text { Falta de espaço para } \\
\text { circulação dentro da } \\
\text { unidade. Ambientes de } \\
\text { banho e preparo de } \\
\text { medicação } \\
\text { subdimensionados. }\end{array}$ & Acidentes & $\begin{array}{l}\text { Redistribuição interna de } \\
\text { leoiute (arranjo de móveis). }\end{array}$ \\
\hline
\end{tabular}

Quadro 06 - Avaliação Preliminar de Riscos Ergonômicos

\begin{tabular}{|l|l|l|l|}
\hline \multicolumn{1}{|c|}{ PERIGOS } & \multicolumn{1}{|c|}{ PROVÁVEIS CAUSAS } & \multicolumn{1}{c|}{ DANO } & \multicolumn{1}{c|}{ RECOMENDAÇÕES } \\
\hline $\begin{array}{l}\text { Carga Excessiva de } \\
\text { Trabalho Probabilidade: } \\
4\end{array}$ & $\begin{array}{l}\text { Diversos profissionais trabalham em } \\
\text { mais de um local. Poucas folgas. }\end{array}$ & $\begin{array}{l}\text { Ansiedade, } \\
\text { angústia, } \\
\text { depressão, } \\
\text { insônia. }\end{array}$ & $\begin{array}{l}\text { Revisão das escalas de } \\
\text { trabalho. }\end{array}$ \\
$\begin{array}{l}\text { Categoria de Risco: } 8 \\
\text { Prioridade: Muito Alta }\end{array}$ & & $\begin{array}{l}\text { Sobrecarga de atividades, ambiente } \\
\text { de trabalho tenso, rotina de trabalha } \\
\text { intensa, riscos, carga de trabalho } \\
\text { elevada, tarefas complexas, rápida } \\
\text { tomada de decisões, choro constante } \\
\text { de pacientes. }\end{array}$ & $\begin{array}{l}\text { Ansiedade, } \\
\text { angústia, } \\
\text { depressão, } \\
\text { insônia. }\end{array}$ \\
$\begin{array}{l}\text { Probabilidade: } 4 \\
\text { Gravidade: } 4\end{array}$ & $\begin{array}{l}\text { Apoio Psicológico à equipe } \\
\text { oferecido pela Gestão. }\end{array}$ \\
Prioridade: Muito Alta & & \\
\hline
\end{tabular}

Percebe-se que os riscos psicossociais, afetam a maioria dos outros, pois durante o exercício da profissão não é possível separar cada aspecto do trabalhador. Ele é um todo, que deve ser tratado como tal. Por ser uma pesquisa qualitativa, não foram realizados questionários sobre fatores de risco psicológico e social, mas ao acompanhar seu dia-a-dia tornaram-se evidentes quais são.

Neste caso, será necessária assistência psicológica, sensibilização e conscientização dos trabalhadores. Muitas vezes estão acostumados com o ambiente e as condições de trabalho estressantes que acabam nem percebendo o quanto tais fatores os afetam, podendo trazer diversas consequências já mencionadas neste estudo. 


\section{CONSIDERAÇÕES FINAIS}

Neste estudo ficou evidenciado que os profissionais da enfermagem que trabalham na UTIN estão expostos com frequência aos fatores de risco que corroboram para ocorrência de acidentes e doenças ocupacionais possuindo relação com suas atividades laborais.

Concluiu-se que os principais riscos ocupacionais, classificados aqui como de altos ou muito altos, aos quais os trabalhadores estão expostos são: riscos físicos ligados a radiação ionizante; ao risco de acidentes ligados a falta de sinalização de segurança; aos riscos ergonômicos e de acidentes ligados a falta de acessibilidade e dos riscos ergonômicos ligados à carga excessiva de trabalho e stress. Esses riscos também foram apontados por Portela et al. (2021) e Santos et al. (2020).

Sabe-se que os acidentes de trabalho e as doenças ocupacionais decorrem de um contexto organizacional e, por isso, se faz necessária a revisão da política de gestão de riscos aos trabalhadores, de forma que se possa estabelecer ações integradas envolvendo SESMT, CCIH e colaboradores, visando a sensibilização, conscientização, treinamento da equipe, para diminuir a frequência e quantidade de exposição do trabalhador aos fatores de risco.

Deverá ser feita concentração de recursos e esforços para mudança na organização interna e redistribuição do layout, destacando que deve ser aberto à participação ativa dos envolvidos no setor, para garantir a satisfação dos servidores e atenda tanto a parte técnica quanto a ergonomia necessária. Propõe-se a implementação de programas de prevenção e conscientização de práticas seguras e formação continua da equipe, afim de conhecer as formas de adoecimento ocupacional, identificando suas causas e efeitos no ambiente de trabalho.

Espera-se que este estudo possa contribuir para o conhecimento dos riscos aos quais os enfermeiros estão expostos na UTIN, em especial a equipe de enfermagem, para que cientes dos riscos sejam realizadas medidas preventivas e corretivas de modo a proporcionar maior segurança para os integrantes da equipe de trabalho e pacientes.

\section{REFERÊNCIAS}

ALMEIDA, L. M. N.; Beltrame Junior, M.; Salazar, M. B. P. Unidade de terapia intensiva neonatal: riscos físicos como fatores potenciais de agravos à saúde do trabalhador. Revista Univap, v. 20, n. 35, 2014.

BALTHAZAR, M. A. P. et al. Gestão dos Riscos Ocupacionais nos Serviços Hospitalares: Uma Análise Reflexiva. Revista de Enfermagem UFPE online, v. 11, n. 9, pp. 3482-91, 2017.

BRASIL. Portaria n. ${ }^{\circ} 3.214,08$ de junho de 1978. "Aprova as Normas Regulamentadoras NR - do Capítulo V, Título II, da Consolidação das Leis do Trabalho, relativas a Segurança e Medicina do Trabalho". Disponível em: https://www.gov.br/trabalho-e-previdencia/ptbr/composicao/orgaos-especificos/secretaria-de-trabalho/inspecao/seguranca-e-saude-notrabalho/sst-portarias/1978/portaria_3-214_aprova_as_nrs.pdf. Acesso em: nov, 2021.

BRASIL. Agência Nacional de Vigilância Sanitária. Conforto Ambiental em

Estabelecimentos Assistenciais de Saúde. 165 p. Agência Nacional de Vigilância Sanitária. Brasília, 2014.

BRASIL. Agência Nacional de Vigilância Sanitária. Higienização das mãos em serviços de saúde. 53 p. Agência Nacional de Vigilância Sanitária. Brasília, 2007. 
Durante, L. C.; Marques, N. A. A. L. T.; et al; Riscos Ocupacionais Evidenciados em uma Unidade de Terapia intensiva Neonatal: Um Estudo de Caso. ES - Engineering and Science, 2021, 10:3.

CARDELLA, B. Segurança no Trabalho e Prevenção de Acidentes: Uma Abordagem Holística. 254 p. Editora Atlas: São Paulo. 2007.

CAVAlCANTE, C. A. A.; ENDERS, B. C.; MENEZES, R. M. P.; MEDIEROS, S. M. Riscos Ocupacionais do Trabalho em Enfermagem: Uma Análise Contextual. Ciência, Cuidado e Saúde, v. 5, n. 1, p. 88-97, 2006.

DIAS, I. F. L. et al. Efeitos da luz em sistemas biológicos. Semina: Ciências Exatas e Tecnológicas, v. 30, n. 1, p. 33-40, 2009.

DIAS, M. H. C. et al. Considerações sobre os Efeitos à Saúde Humana da Irradiação Emitida por Antenas de Estações Rádio-base de Sistema Celulares. Revista Cientifica Periódica de Telecomunicações. CETUC. PUC-Rio. Rio de Janeiro; 2002.

ESIN, M. N.; SEZGIN, D. Intensive Care Unit Workforce: Occupational Health and Safety. Intensive Care. IntechOpen, 2017. Disponível em:

https://www.intechopen.com/chapters/54793. Acesso em: nov, 2021.

FIOCRUZ. Fundação Osvaldo Cruz. Guia para Sistemas de Gestão de Saúde e Segurança Industrial. 1996. Disponível em:

http://www.fiocruz.br/biosseguranca/Bis/manuais/seguranca\%20e\%20saude $\% 20$ no $\% 20$ trabal ho/SISTEMAS\%20DE\%20GESTO\%20DE\%20SADE\%20E\%20SEGURANA\%20INDUST RIAL.pdf. Acesso em: nov, 2021.

LEITÃO, I. M. T. A.; FERNANDES, A. L.; RAMOS, I. C. Saúde ocupacional: Analisando os riscos relacionados à equipe de enfermagem numa unidade de Terapia Intensiva. Ciência Cuidado e Saúde, vol. 7, n. 4, p. 476 -484, 2008.

MARTINS, J. T. Prazer e sofrimento no trabalho do enfermeiro em Unidades de Terapia Intensiva: estratégias defensivas. 199fl. Tese (doutorado) - Escola de Enfermagem de Ribeirão Preto, Universidade de São Paulo, 2008.

MEDEIROS, A. L.; COSTA, M. B. S; SOUSA, M. C. J.; ROSENSTOCK, K. I. V. Gerenciamento de Riscos e Segurança no Trabalho em Unidades de Saúde da Família. Revista Brasileira de Ciências da Saúde. v. 17, n. 4, p. 341-348, 2013.

MTE. Ministério do Trabalho e Emprego. Nota Técnica 060 - Ergonomia - indicação de postura a ser adotada na concepção de postos de trabalho. 2001. Disponível em: https://docplayer.com.br/3805158-Nota-tecnica-060-2001-assunto-ergonomia-indicacao-depostura-a-ser-adotada-na-concepcao-de-postos-de-trabalho.html. Acesso em: nov, 2021.

MUSHAUSEN, J. R.; DAMIANO, J. A strategy for assessing and managing occupational exposures. Fairfax, Virginia: AIHA, 1998.

NAZARIO, E. G.; CAMPONOGARA, S.; DIAS, G. L. Occupational risks and adherence to standard precautions in intensive care nursing work: workers' perceptions. Rev. bras. saúde ocup., v. 42, 2017.

PORTELA, R. SILVA; LEMOS, T. A. B.; MARQUES, K. M. S.; MARQUES, B. B.; ROCHA, I. M.; RIBEIRO, L. M.; CARVALHO, A. F. M.; CARVALHO, G. D.; SILVA, M. A.; FEITOSA, M. C. P. Análise ergonômica da UTI Neonatal e a sua influência sobre as 
Durante, L. C.; Marques, N. A. A. L. T.; et al; Riscos Ocupacionais Evidenciados em uma Unidade de Terapia intensiva Neonatal: Um Estudo de Caso. ES - Engineering and Science, 2021, 10:3.

lesões nos profissionais de saúde. Research, Society and Development, v. 10, n. 9, e35910918196-e35910918196, 2021.

SANTOS, R. C.; ALVES, A. P. B.; MILHOMEM, A. B.; AMARAL, M. S. Riscos ocupacionais durante assistência de enfermagem em unidade de terapiaintensiva: uma revisão integrativa. Braz. J. of Develop., v. 6, n. 12, p.101349-101356, 2020.

SARAIVA, C. A. S. Fatores Físicos-Ambientais e Organizacionais em Uma Unidade de Terapia Intensiva Neonatal: Implicações para Saúde do Recém-Nascido. 103fl. Tese (mestrado) - Escola de Engenharia, Universidade Federal do Rio Grande do Sul, 2004.

SCALDELAI, V. S.; OLIVEIRA, C. A. D; MILANELI, E.; OLIVEIRA, J. B. C.; BOLOGNESI, P.R. Manual Prático de Saúde e Segurança no trabalho, $1^{\text {a }}$ ed., p. 458, Yendis Editora: São Caetano do Sul, 2009.

SESI. Serviço. Social da Indústria. Mapa de Riscos de Acidentes do Trabalho - Guia Prático. 63 p. São Paulo: Gráfica Bandeirantes, 1994.

VENDRAME, A. C. Gestão do Risco Ocupacional. 191p. IOB Thomson. São Paulo, 2005.

VIVAN, P. J.; LINS, J. F. A. B. A.; DURANTE, L. C. Conforto Acústico - Avaliação de uma UTI Neonatal. Saarbrucken: Novas Edições Acadêmicas, 2013. 